Int. J. Dev. Biol. 61: 611-620 (2017)

doi: $10.1387 / \mathrm{ijdb} .170251 \mathrm{vs}$

\title{
Left-right asymmetry specification in amphioxus: review and prospects
}

\author{
VLADIMIR SOUKUP* \\ Institute of Molecular Genetics of the Czech Academy of Sciences, Prague, Czech Republic,
}

\begin{abstract}
Extant bilaterally symmetrical animals usually show asymmetry in the arrangement of their inner organs. However, the exaggerated left-right (LR) asymmetry in amphioxus represents a true peculiarity among them. The amphioxus larva shows completely disparate fates of left and right body sides, so that organs associated with pharynx are either positioned exclusively on the left or on the right side. Moreover, segmented paraxial structures such as muscle blocks and their neuronal innervation show offset arrangement between the sides making it difficult to propose any explanation or adaptivity to larval and adult life. First LR asymmetries can be traced back to an early embryonic period when morphological asymmetries are preceded by molecular asymmetries driven by the action of the Nodal signaling pathway. This review sums up recent advances in understanding LR asymmetry specification in amphioxus and proposes upstream events that may regulate asymmetric Nodal signaling. These events include the presence of the vertebrate-like LR organizer and a cilia-driven fluid flow that may be involved in the breaking of bilateral symmetry. The upstream pathways comprising the ion flux, Delta/Notch, Wnt/ $\beta$-catenin and Wnt/PCP are hypothesized to regulate both formation of the LR organizer and expression of the downstream Nodal signaling pathway genes. These suggestions are in line with what we know from vertebrate and ambulacrarian LR axis specification and are directly testable by experimental manipulations. Thanks to the phylogenetic position of amphioxus, the proposed mechanisms may be helpful in understanding the evolution of LR axis specification across deuterostomes.
\end{abstract}

KEY WORDS: amphioxus, bilateral asymmetry, symmetry break, left-right organizer

\section{Introduction}

For vertebrate comparative morphologists, the cephalochordate amphioxus represents a true gem. Thanks to its body plan, amphioxus repeatedly exemplifies a starting point in the scenarios depicting evolution of certain vertebrate traits and, accordingly, a proxy for how the invertebrate ancestor of vertebrates may have looked like. Despite the shared body plan and its phylogenetic position as the earliest branching chordate taxon, amphioxus possesses a particular trait that often largely hinders direct comparison of certain organs and structures with their vertebrate counterparts or requires a great deal of creativity to assign them. This trait is exemplified by the extreme morphological asymmetry that affects development of many organs in the amphioxus body and that is unfound in other animal lineages. All three amphioxus genera (Branchiostoma, Epigonichthys and Asymmetron) show prominent left-right (LR) asymmetry at larval and, to a lesser extent, also at adult stages demonstrating that this trait is inherent to the whole cephalochordate lineage (Holland and Holland, 2010, Igawa et al., 2017). Past researchers have either sought for an adaptive explanation, recapitulation of past evolutionary events or suggested that the amphioxus LR asymmetry is a developmental accident that has been retained early in evolution. Despite the various hypotheses proposing explanations for this extreme LR asymmetry, its molecular regulation has long been overlooked.

The past 20 years have been fruitful in dissecting mechanisms how directive LR asymmetry is established. Although many factors were shown to regulate the LR asymmetry including members of Wnt, Delta/Notch, Fibroblast growth factor, Hedgehog or Bone morphogenetic protein signaling pathways, the central pathway that is directly linked to LR axis specification in a plethora of animals is that involving Nodal. This pathway regulates LR axis by specifying the left side in vertebrates and tunicates (Morokuma et al., 2002,

Abbreviations used in this paper: LR, left-right; LRO, left-right organizer.

*Address correspondence to: Vladimir Soukup. Currently at: Department of Zoology. Faculty of Science, Charles University in Prague, Vinicna 7,
12844 Praha 2, Czech Republic. e-mail: soukup@natur.cuni.cz - (iD) http://orcid.org/0000-0002-1914-283X

Submitted: 5 September, 2017; Accepted: 5 October, 2017

ISSN: Online 1696-3547, Print 0214-6282 
Nakamura and Hamada, 2012) and the right side in echinoderms and presumably also in hemichordates, brachiopods and annelids (Duboc et al., 2005, Grande et al., 2014, Martin-Duran et al., 2016, Wlizla, 2011). In snails, the Nodal pathway regulates coiling of the shell, so that it either acts on the right side in dextrally-coiling species or on the left side in sinisterly-coiling species, with dextrality being probably the ancestral state (Grande and Patel, 2009, Kuroda et al., 2009). Besides ecdysozoans, where LR asymmetry is likely regulated through Nodal-independent mechanisms, Nodal signaling seems to be a widespread feature regulating body asymmetry (Coutelis et al., 2014, Grande et al., 2014, Namigai et al., 2014). Nodal pathway has even been found to direct positioning of asexual budding of new polyps in Hydra (Watanabe et al., 2014). Regulation of asymmetry by the Nodal signaling thus dates back at least to the common ancestor of bilaterians and cnidarians and thus predates the origin of bilaterality. In bilaterians, the difference in the site of action of the Nodal pathway (left in chordates, right in non-chordates) is most likely due to the dorso-ventral inversion of body axes that occurred at the base of the chordate phylogeny (Arendt and Nubler-Jung, 1994, De Robertis and Sasai, 1996) and that resulted in a concomitant flipping of left and right sides.

In mouse, the Nodal pathway involves action of the Nodal ligand, its cofactor Gdf1 and its downstream effector Pitx2 on the left side, and its extracellular antagonists Cerberus-like2 on the right side, Lefty 1 in the midline and Lefty2 on the left side (Shen, 2007). In amphioxus, the Nodal pathway is conserved in its entirety and similarly to vertebrates, its members are expressed on the left side in case of Nodal, Gdf1/3, Pitx and Lefty and on the right side in case of Cerberus (Le Petillon et al., 2013, Onai et al., 2010, Yasui et al., 2000, Yu et al., 2002a, Yu et al., 2007). Amphioxus thus shares a basic arrangement of asymmetrically expressed genes with vertebrates, making it an ideal model for understanding the basis of LR asymmetry specification in chordates.

One of the most important questions concerning LR asymmetry development is the initial break of the bilateral symmetry. Although concerns exist on the time point and the actual cause of this break (Blum et al., 2014b, McDowell et al., 2016, Namigai et al., 2014, Vandenberg and Levin, 2013), several mechanisms may act in concert to direct the asymmetric activity of the Nodal signaling. Besides activity of the upstream pathways that trigger expression of Nodal, LR asymmetry in vertebrates is directly linked to the presence of the LR organizer (LRO) and the fluid flow it produces. Here, I sum up the current state of knowledge on the LR axis specification in amphioxus and propose mechanisms that may act upstream of the asymmetric expression of the Nodal pathway and that may be important for LR axis development, including the upstream pathways and the presence of the LRO. Although hard evidence for most of the proposed mechanisms is currently lacking, comparison with LR asymmetry specification in vertebrate and sea urchin embryos hints to equivalent events taking place during amphioxus LR axis development.

This review does not intend to evaluate morphogenesis of asymmetrically placed organs, homologies with their vertebrate or ambulacrarian counterparts or adaptivity of the amphioxus asymmetry, for which the reader is referred to elsewhere (Kaji et al., 2016, Lacalli, 2008, Soukup and Kozmik, 2016, Stach, 2000, Willey, 1894). Instead, it intends to complement our understanding on LR axis specification in amphioxus with fresh insights into recent interests in studying evolution of LR asymmetry in deuterostomes.

\section{Amphioxus morphological asymmetries}

Morphological asymmetries of the amphioxus larva have been known since the first descriptions of amphioxus embryonic and larval development (Conklin, 1932, Hatschek, 1893, Willey, 1891), yet their profound presence in this animal has not stopped to fascinate researchers even nowadays. This has been caused by the fact that, unlike e.g. in vertebrates, the LR asymmetry in amphioxus affects development of the whole body, involving not only the internal, but also the external morphology.

LR asymmetry is most conspicuous at larval stages, especially affecting morphogenesis of paraxial structures and pharyngeal organs (Fig. 1). The body segments containing muscle blocks show offset arrangement with the left set positioned more anteriorly than the right set. Accordingly, the axons of peripheral nerves that innervate these segments, but also neurons within the neural tube, show comparable offset arrangement. Within the pharyngeal region, left and right sides undergo completely disparate fates. The mouth opens on the left side. The oral papilla differentiates from the left-sided epidermis anterior to the mouth. The precursor of the supposed homolog of the vertebrate anterior pituitary, the preoral pit, develops from the left endodermal pouch that fuses with the epidermis anterior to the mouth. The right endodermal pouch, on the other hand, gives rise to the cephalic coelom. The homolog of the vertebrate thyroid gland, the endostyle, develops from the right pharyngeal wall opposite to the mouth. The club-shaped gland, which is a tube with no clear vertebrate counterpart, surrounds the pharynx so that its glandular portion opens into the pharynx on the right side behind endostyle, while its afferent duct opens to the exterior below the mouth on the left side. The pharyngeal asymmetry is further underlined by the development of gill slits. In Branchiostoma, gill slits are sequentially added at the ventral midline but the anteriormost ones are subsequently shifted slightly towards the right side. In Asymmetron, on the other hand, the first gill slit develops slightly leftward from the midline (Holland and Holland, 2010). In addition, several small epidermal glands show asymmetric placement (van Wijhe, 1925) and the anus opens on the right side. The profound asymmetry in the pharyngeal region is, indeed, reflected by the associated musculature and innervation (Kaji et al., 2009, Yasui et al., 2014). Comparison of larval development between different species shows only subtle differences in the arrangement of the asymmetrically placed organs demonstrating that the larval asymmetry is a general feature of the amphioxus lineage (Holland and Holland, 2010).

During metamorphosis, the pharyngeal region undergoes massive rearrangements resulting in the partial restoration of the bilateral symmetry. However, some structures remain asymmetrically arranged or placed on one side until adulthood. Most prominent is the continued offset arrangement between left and right sides of the segmented organs including body musculature, central and peripheral nervous system, gill slits and gonads. Besides that, the hepatic diverticulum develops as the right-sided outgrowth of the digestive tract and in Asymmetron and Epigonichthys, only the right-sided gonads develop (Igawa et al., 2017).

First morphological signs of the LR asymmetry in amphioxus appear at mid-neurula stage with five pairs of somites, where the left set of somites shows a slight anterior shift as compared to the right set (Minguillon and Garcia-Fernandez, 2002, Soukup et al., 2015). The somitic asymmetry is further pronounced at the late 
neurula and subsequent stages and this asymmetry is mimicked by asymmetries in the neural tube and adjoining axons of peripheral nerves (Bardet etal., 2005, Candiani et al., 2006, Yasui et al., 1998). Late neurulae also show first asymmetrical expression of factors related to development of pharyngeal organs (Candiani et al., 2008, Venkatesh et al., 1999, Wang et al., 2002, Yu et al., 2002b, Zhang and Mao, 2010). Judging from these early morphological asymmetries, stages prior to the $\mathrm{mid} /$ late neurula are expected to exhibit LR asymmetry specification events.

\section{Signaling pathways regulating amphioxus left-right asymmetry}

Previous reports have found asymmetric expression of members of the LR asymmetry-specifying Nodal signaling pathway in amphioxus from early through hatching to mid-neurula stages (Le

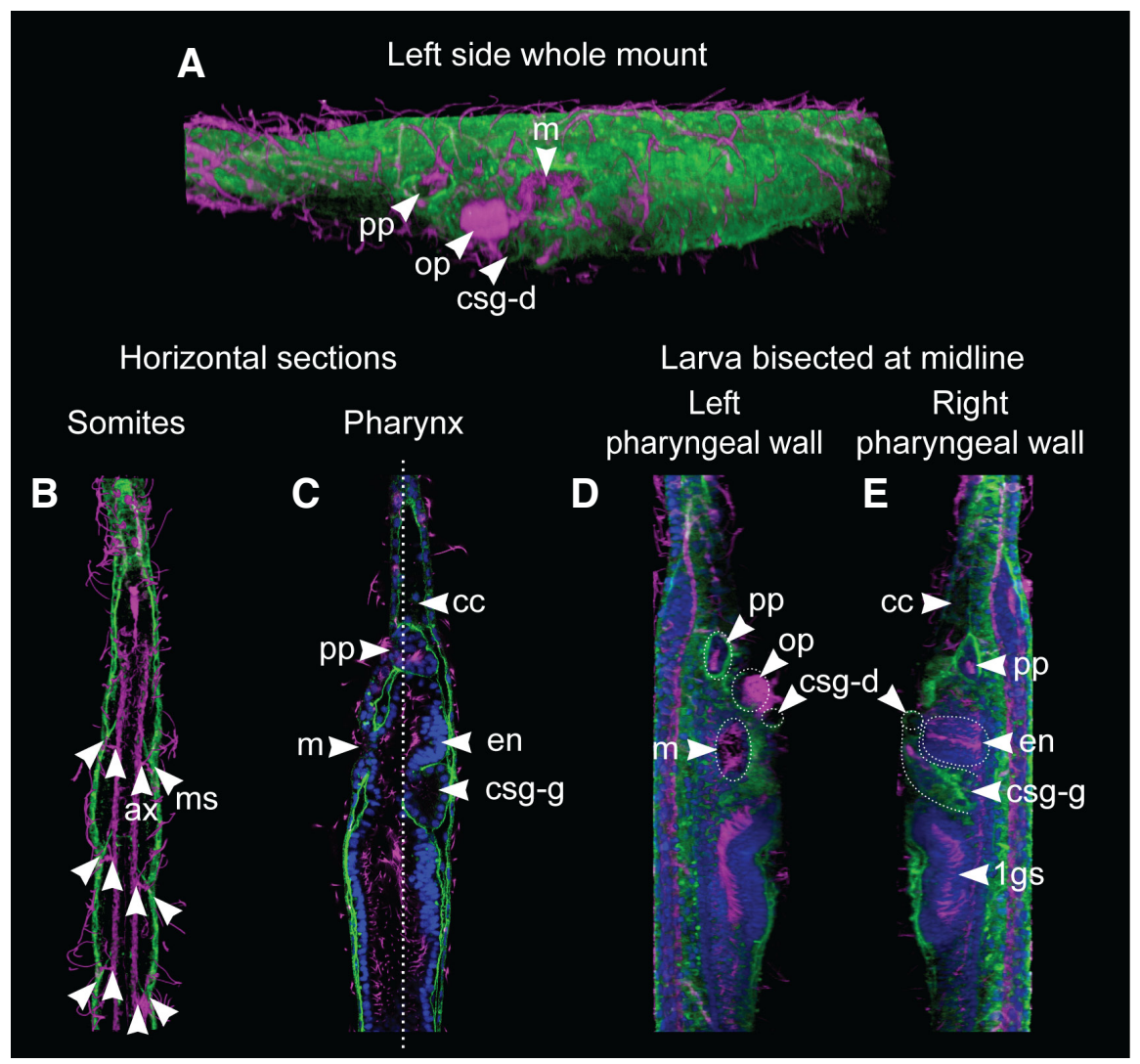

Fig. 1. Amphioxus larva exhibits a marked left-right asymmetry. (A) Whole mount view at structures developing on the left side shows position of the mouth $(m)$, the preoral pit (pp), the oral papilla (op) and the orifice of duct of the club-shaped gland (csg-d). (B) Optical section through the paraxial structures depicts the offset arrangement of borders between anterior most muscle segments (ms) and axons of peripheral nerves (ax). (C) Horizontal optical section through the pharyngeal region shows position of the left-sided structures, such as the mouth (m) and the preoral pit (pp), and the right-sided structures such as the cephalic coelom (cc), the endostyle (en) and the glandular part of the club-shaped gland (csg-g). (D,E) Views from the median plane at left and right halves of a bisected pharynx (level of bisection indicated by a broken line in C) show left-sided placement of the mouth $(\mathrm{m})$, the preoral pit (pp), the ora papilla (op) and the orifice of duct of the club-shaped gland (csg-d), and right-sided placement of the cephalic coelom (cc), the endostyle (en), the glandular part of the club-shaped gland (csgg) and the first gill slit (1gs). Laminin (green channel) marks basal laminae, acetylated tubulin (magenta channel) marks cilia and axons of neurons; DAPI (blue channel) stains cell nuclei.
Petillon et al., 2013, Onai et al., 2010, Yasui et al., 2000, Yu et al., 002a). The pathway involves factors expressed preferentially on (hide such as Nodal, its cofactor Gdr1/3(Vg1), its repressor Cerberus acting on the right side. The change in the expression of Cerberus from bilateral to right-sided at late gastrula/early by the asymmetric expression of Lefty, Pitx, Nodal and Gdf1/3. course experiments with a pharmacological inhibitor of Nodal confirmed period spanning the early, hatching and midmorphological asymmetries in amphioxus (Soukup et al., 2015). By analogy with vertebrates, a model has been proposed (Fig. 2A), wherein Cerberus inhibits Nodal on the right side, thus restricting action of the Nodal pathway to the left side. The left-sided activity of Nodal would in turn repress the left-sided expression of Cerberus, activate expression of Nodal, Gdf1/3, Lefty and Pitx and promote development of the left side. Lefty would act as a regulator of Nodal ligand activity by preventing it to trigger left-sided fate on the right side, while Pitx would convey the left side-specific morphogenesis (Soukup et al., 2015).

Recently, Li et al., (Li et al., 2017) have confirmed this model by deciphering the molecular interactions of members of this pathway using TALEN-mediated knock-out lines, mRNA injections and heat-shock promoter-driven overexpression experiments and showed that the Nodal signaling pathway acts to specify the left side in a similar fashion as in vertebrates. Knockout of $\mathrm{Cer}$ berusresults in the ectopic right-sided expression of Nodal, Lefty and Pitx, while overexpression of Cerberusleads to loss of the left-sided expression of these factors. Overexpression of Nodal in turn represses the right-sided expression of Cerberus and activates ectopic right-sided expression of Lefty and Pitx, while pharmacological inhibition of Nodal signaling leads to bilateral expression of Cerberus and loss of Lefty and Pitx expression. Further gain- and loss-of-function experiments confirmed that Lefty acts as a feedback inhibitor of Nodal (Li et al., 2017). The way Nodal pathway works to specify the left side in amphioxus is in good agreement with what has been shown in vertebrates, with an exception that Pitx, the effector of Nodal pathway, feeds back to activate Nodal (Fig. 2A), which has not been found either in vertebrates or in echinoderms (Li et al., 2017). Whether this interaction buffers the antagonistic activity of Lefty on Nodal or whether it helps to sustain the expression of Nodal to larval stages to promote prolonged action of this pathway on the left side (see Schubert et al., 2005, Yu et al., 2002a) remains to be elucidated.

The molecular readouts of these gain- and loss-of-function experiments are reflected in the larval morphology. The larvae display left or 


\section{V. Soukup}

right isomerism depending on whether expression of the left sidedetermining Pitx becomes ectopically activated on the right side, or whether it becomes downregulated on the left side (Fig. 2B) (Li et al., 2017). Both phenotypes are unviable. Larvae exhibiting the left isomerism show duplication of mouth, preoral pit, ventral portion of endostyle and duct of the club-shaped gland, whereas larvae with right isomerism show duplication of cephalic coelom, endostyle and glandular portion of the club-shaped gland and both phenotypes also display symmetrization of body segments (Ber- trand et al., 2015, Kaji et al., 2016, Li et al., 2017, Soukup et al., 2015). Indeed, symmetrization of body segments differs between larvae exhibiting the left or right isomerism, i.e. the symmetrization occurs according to the original position of the left or the right set of somites, respectively (Fig. 2B).

A marked difference between amphioxus and vertebrate LR axis development is related to the transcription factor $\mathrm{FoxH}$, whose vertebrate orthologs are associated with Nodal signaling pathway by promoting the asymmetric signal through interactions with Smad2

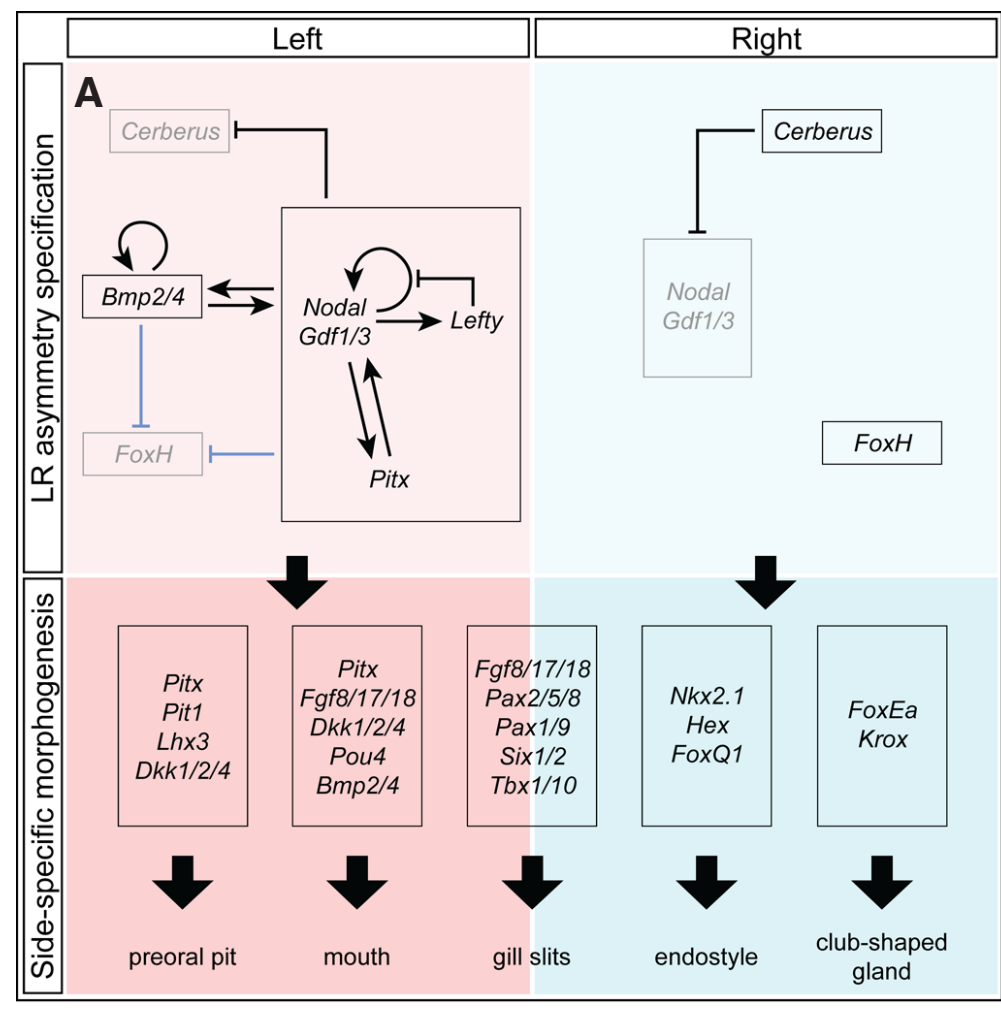

C 1. Breaking of LR symmetry

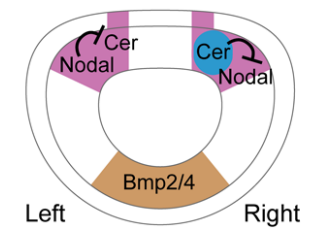

2. LR asymmetry specification

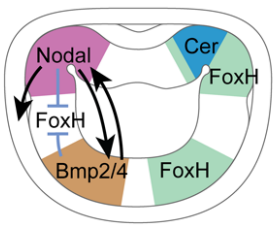

3. Determination of the sides

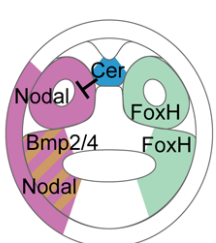

B

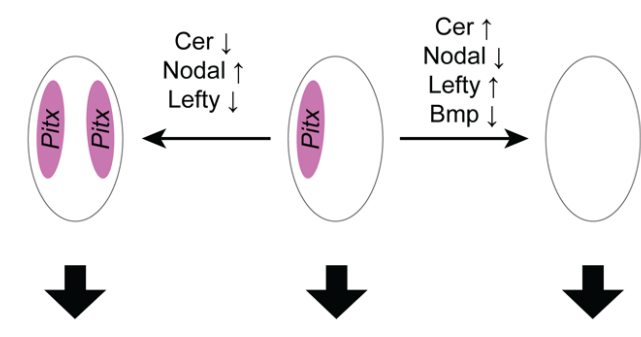

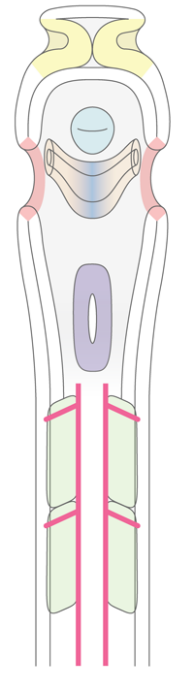

left isomerism

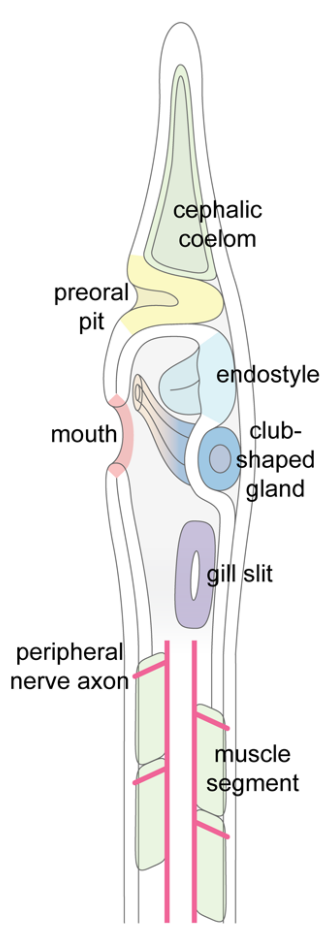

LR asymmetry

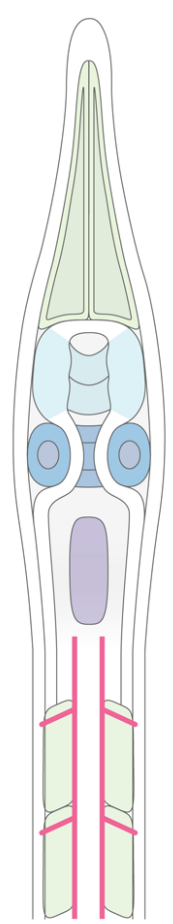

right isomerism

Fig. 2. Regulation of left-right (LR) asymmetry in amphioxus. (A) Specification of $L R$ axis involves the initial interplay between Cerberus and Nodal factors. On the right side, expression of Cerberus represses triggering of the Nodal pathway. On the left side, Nodal activates its own expression and expression of its cofactor Gfd1/3, its antagonist Lefty and its agonist Pitx. The Nodal pathway further acts in concert with the Bmp pathway (through Bmp2/4) to specify the left side. Nodal and/or Bmp pathways inhibit FoxH on the left side rendering its expression to the right side. The differential specification of left and right sides leads to disparate determination through upregulation of the downstream organ-specific factors. Proposed interactions are marked blue. (B) Affection of pathways regulating $L R$ asymmetry results in altered expression of Pitx and in phenotypes exhibiting isomerisms of body sides. Downregulation of Cerberus or Lefty or upregulation of Nodal leads to the ectopic expression of Pitx on the right side and subsequently in the left isomerism. Conversely, upregulation of Cerberus or Lefty or downregulation of Nodal (but also downregulation of Bmp signaling) results in the loss of Pitx expression and in subsequent right isomerism. (C) A model of spatio-temporal distribution of factors regulating LR asymmetry specification at neurula stages. LR asymmetry is broken by expression of Cerberus in right presomitic mesoderm and its inhibitory action on Nodal. This leads to specification of left and right sides by restriction of the Nodal signaling to the left side, where it interacts with the Bmp signaling. The Nodal pathway spreads from the left presomitic mesoderm to the adjacent endoderm and ectoderm, while expression of FoxH becomes restricted to the right side. Expression of Cerberus shifts from the right presomitic mesoderm to the ventral neural tube to further restrict the action of the Nodal signaling to the left side. The differential expression on left and right sides subsequently triggers asymmetric gene expression and asymmetric morphology. 
and Smad4 and binding to asymmetric enhancers of Nodal, Lefty2 and Pitx2 genes (Adachi et al., 1999, Chen et al., 1997, Norris et al., 2002, Osada et al., 2000, Pogoda et al., 2000, Saijoh et al., 2000, Shiratori et al., 2001). In contrast to vertebrates, FoxH in amphioxus is expressed in the right ventral foregut and right somites from stages of the asymmetrical expression of Nodal onwards suggesting that FoxH may promote the right-sided morphogenesis (Soukup and Kozmik, manuscript submitted). Upon inhibition of the Nodal signaling, FoxH becomes ectopically expressed on the left side. FoxH thus seems to promote signaling of a yet unidentified pathway that regulates development of the right side, while Nodal activity is likely promoted through a different transcription factor, possibly a different Fox.

In vertebrates and in echinoderms, Bmp pathway interacts with Nodal pathway by either activating it or restricting it towards one side and these interactions may be stage and species specific (Chocron et al., 2007, Katsu et al., 2013, Luo and Su, 2012, Mine et al., 2008, Piedra and Ros, 2002, Schlange et al., 2002). In amphioxus, pharmacological inhibition of Bmp signaling at stages spanning LR asymmetry specification produces right-sided mirror image morphology in both paraxial and pharyngeal regions, thus phenocopying larvae upon inhibition of Nodal signaling (Fig. 2B, Soukup and Kozmik, manuscript submitted). Examination of expression patterns of Bmp ligands uncovered left-sided bias in the $B m p 2 / 4$ expression in the ventral foregut that temporarily coincides with the onset of the asymmetric expression of Nodal. Downregulation of Bmp signaling leads to loss of the left-sided expression of Bmp2/4, Nodal, Gdf1/3, Lefty and Pitx and to the ectopic expression of Cerberus and FoxH. Conversely, downregulation of Nodal signaling leads to loss of the Bmp2/4 expression, although the overall Bmp signaling activity remains unaffected (Soukup and Kozmik, manuscript submitted). Nonetheless, these experiments suggest that Bmp (possibly through Bmp2/4) and Nodal pathways act in concert to specify the left side.

To sum up the current state of knowledge into a model of LR axis specification in amphioxus (Fig. 2C), the initial break of the bilateral symmetry is provided by the asymmetric expression of Cerberus in the right presomitic mesoderm at the time, when Nodal is expressed symmetrically. The antagonistic action of Cerberuson Nodal on the right side restricts the activity of the Nodal signaling to the left presomitic mesoderm, from which the Nodal signal is transferred to the surrounding ectodermal and endodermal tissues. Nodal from the presomitic mesoderm forms a feedback loop with $B m p 2 / 4$ from the ventral foregut and either or both factors inhibit FoxH, whose expression is restricted to the right presomitic mesoderm and right anterior foregut. Expression of Cerberus shifts from right presomitic mesoderm to the floor plate, where, supposedly, it further restricts action of the Nodal signaling to the left side. From this moment on, each side develops side-specific morphologies through upregulation of downstream organ-specific factors under the influence of the positive Bmp2/4-Nodal-Pitx or the negative Bmp2/4-Nodal-FoxH signaling, respectively (Fig. 2A).

\section{Breaking of bilateral symmetry: towards identification of the left-right organizer}

While presence and function of the Nodal pathway in amphioxus confirms the widespread feature in LR axis establishment, events that take place prior to the asymmetric Nodal expression and are responsible for the initial break of the bilateral symmetry of the amphioxus embryo are generally far less clear. In vertebrates, breaking of the bilateral symmetry is linked with the function of a transient population of cells at the dorsal wall of the primitive gut, the LR organizer (LRO). Vertebrate LROs show a surprising morphological diversity, however they all possess cells with motile cilia that beat in a fashioned way and generate a leftward flow of the surrounding fluid (Blum et al., 2009, Hirokawa et al., 2006). This directional flow leads to local differences between left and right sides of LRO that trigger the side-specific expression of factors such as Nodal or Cerberus (Nakamura et al., 2012, Schweickert et al., 2010). Blum et al., (Blum et al., 2014a, Blum et al., 2009) have speculated that thanks to the comparable tissue context in amphioxus and vertebrate embryos, the vertebrate-like LRO could be found also in amphioxus. This is an interesting area of study since amphioxus shares a common body plan with vertebrates and often reflects prerequisites or primitive states of vertebrate characters. Thus, if we apply features of vertebrate LROs to the amphioxus system, the proposed amphioxus LRO should be 1) a population of ciliated cells located in the dorsal wall of archenteron that would eventually incorporate into the developing notochord, 2 ) in order to be functional, it should contain cells with posteriorly polarized and tilted cilia that beat in a fashioned order to generate the leftward flow, 3) the ciliated flow-generating cells should be surrounded by cells that are sensitive to the flow and that trigger laterality specifying signals, and 4) presence of the LRO should take place at time periods, when expression of Nodal changes from bilateral to left-sided. Reflecting these criteria, several hints have led to the proposition of presence of the LRO in amphioxus.

The archenteron in sea urchins possesses cells with posteriorly tilted cilia that are motile and that trigger asymmetric expression of Nodal (Takemoto et al., 2016, Tisler et al., 2016). This suggests that the cilia-driven LRO dates back to the common ancestor of deuterostomes, which in turn means that such organizer is expected to be present also in amphioxus. The archenteron in the amphioxus gastrula is, indeed, rich in monociliated cells (Hirakow and Kajita, 1991), suggesting a role in flow-mediated LR asymmetry specification, although their structure, position within the cells and motility are unknown. Studies dealing with the direct imaging of the cilia motility, measuring the fluid flow in the archenteron cavity or affecting ciliogenesis or cilia function are still awaited in amphioxus. Markers of motile cilia would help to identify the LRO, however FoxJ1, the master control gene for motile cilia (Yu et al., 2008), does not seem to be expressed in the dorsal roof of the amphioxus archenteron (Aldea et al., 2015), although stages of active LRO may have not been covered by this study. Unfortunately, other factors related to motile cilia, such as Dynein heavy chain-9 or -11 (Left-right dynein) have not been studied in amphioxus. Besides the markers of motile cilia, intra-cellular antero-posterior allocation of planar cell polarity factors, such as Vangl, Prickle, Dvl or other factors would be most informative.

Yet, possibly the best markers of the proposed presence of LRO are the expression patterns of Nodal and Cerberus. Prior to the leftward flow, both factors are expressed bilaterally surrounding the population of cells with beating cilia. In amphioxus, Nodal and Cerberus are co-expressed on both left and right sides in the prospective somitic mesoderm at late gastrula and early neurula stages, while the median region destined to give rise to the anterior notochord is devoid of expression of both genes (Le Petillon et 
al., 2013, Li et al., 2017, Soukup et al., 2015, Yu et al., 2002a). This is in perfect agreement with the LRO proposals suggesting that LRO may well be present in the dorsal roof of the amphioxus archenteron.

\section{Upstream pathways driving left-right asymmetry}

It has been suggested that employment of the LRO may not be the decisive step in the symmetry breakage in deuterostomes, as other mechanisms acting prior to or in parallel seem to contribute to the LR asymmetry specification (Blum et al., 2014b, Su, 2014, Vandenberg and Levin, 2013). In line with this argument, induction of asymmetric expression of Noda/would be a consequence rather than the cause of the symmetry breakage (Namigai et al., 2014). Since the initial pharmacological screen targeting proton pumps and ion channels in Xenopus, it has become clear that changes in the concentration of ions, and thus $\mathrm{pH}$, may regulate LRasymmetry
(Levin et al., 2002). Further pharmacological screens performed in zebrafish, sea squirt and sea urchin embryos confirmed the role of ion flux in LR asymmetric development as a shared character of deuterostomes (Hibino et al., 2006, Shimeld and Levin, 2006, Shu et al., 2007). Application of inhibitors of proton pumps (such as omeprazole or $\mathrm{SCH} 28080$ ) influences the incidence of reversed situs (flipping the left and right sides), left isomerism (duplication of the left side) or right isomerism (duplication of the right side) depending on the concentration of the agent and the species examined (Duboc et al., 2005, Hibino et al., 2006, Levin et al., 2002, Raya et al., 2004, Shimeld and Levin, 2006). Concordantly, application of these inhibitors results in LR phenotypes in the concentration-dependent manner also in amphioxus, suggesting that the ion flux plays similar role in LR axis establishment in this animal (Fig 3) (Bertrand et al., 2015).

How does the activity of ion channels relate to the LR asymmetry? The exact mechanisms are not fully understood and may
A

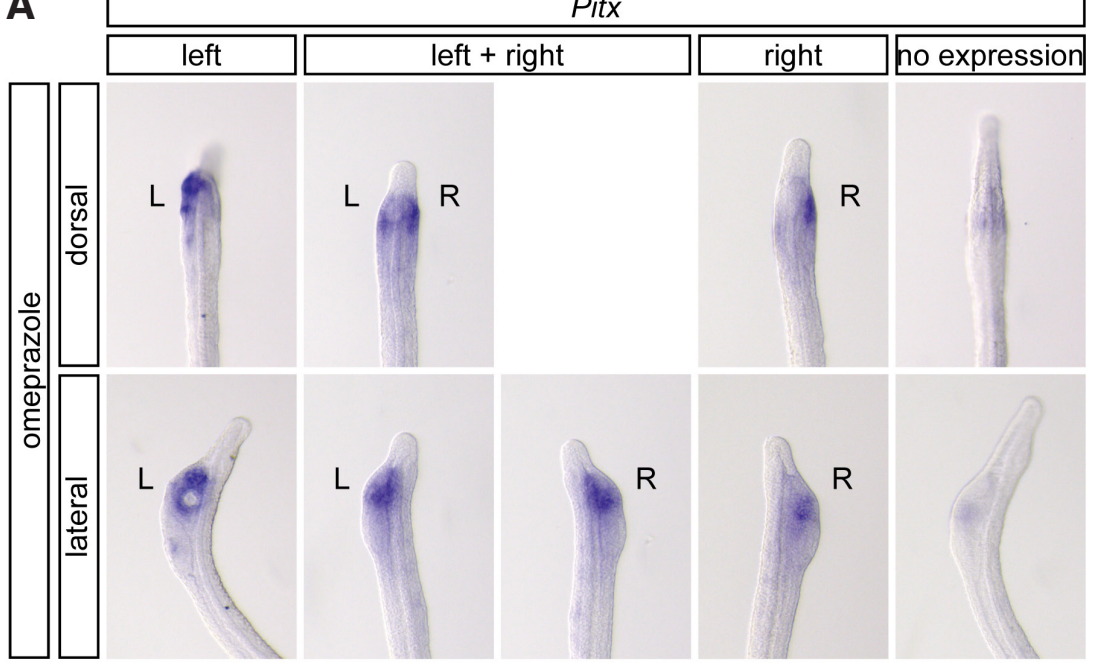

B

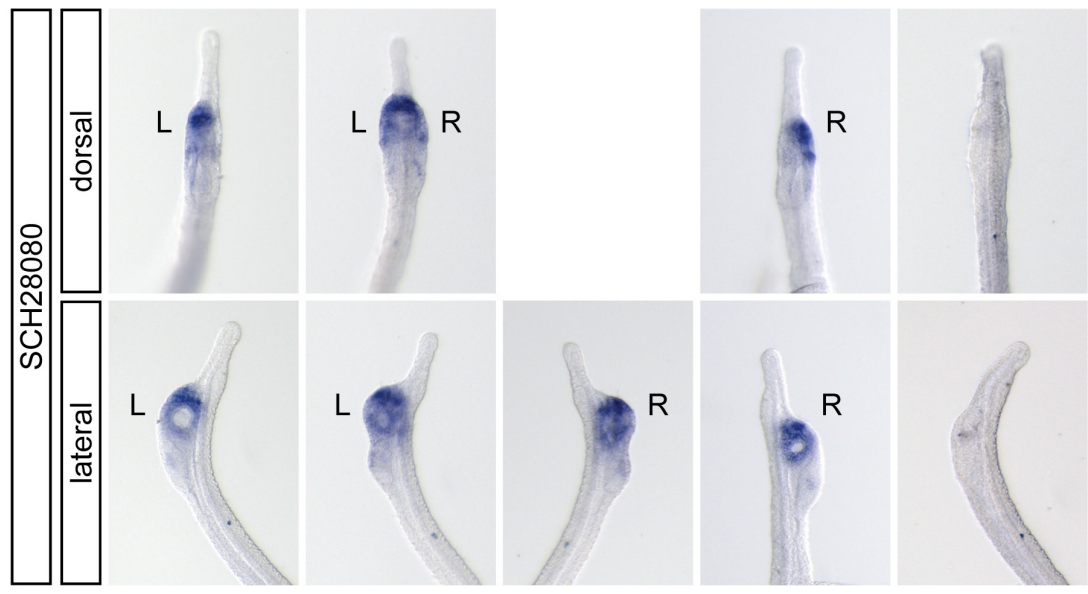

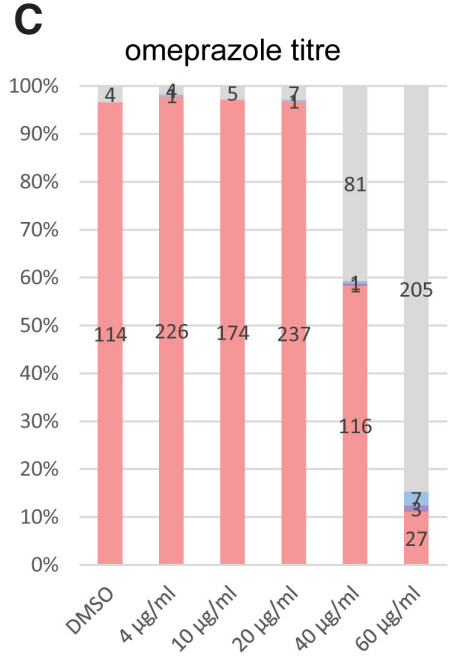

D $\mathrm{SCH} 28080$ titre

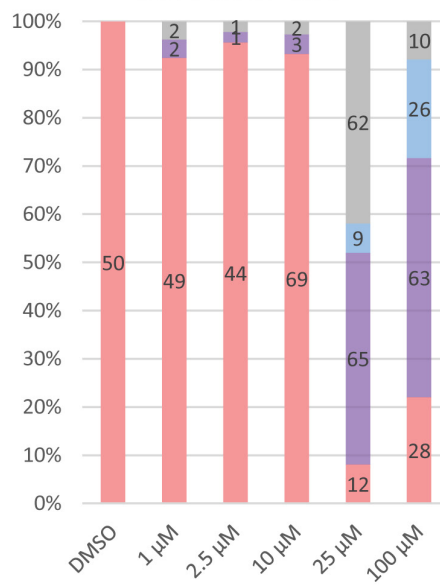

Fig. 3. The role of ion flux in left-right (LR) asymmetry. (A,B) Inhibition of $\mathrm{H}^{+} / \mathrm{K}^{+}$-ATPase by omeprazole or SCH28080 leads to several LR phenotypes identified by the Pitx expression that

marks the morphological left side. Besides normal morphology (left-sided Pitx expression), some larvae display left isomerism (left- and right-sided Pitx expression), right isomerism (no Pitx expression) or flipping of left and right sides (right-sided Pitx expression). Note the different morphology between omeprazole- and SCH28080-treated embryos. (C,D) Titers of omeprazole and SCH28080 show development of different LR phenotypes in a concentration-dependent manner. Treatments were performed from fertilization until open mouth stage when fixed. 
be complex due to the fact that several ion channels supplying the cells with several different ions are involved in LR asymmetry specification and that inhibition of one ion channel potentially affects several downstream pathways (see the discrepancy in phenotypes and their frequency between omeprazole- and $\mathrm{SCH} 28080$-treated amphioxus embryos in Fig. 3). Moreover, the ion flux may be only temporal and highly stage-specific. Besides these uncertainties, the effect of proton pumps and ion channels on LR asymmetry seems to be twofold. In vertebrates, the production of ions is perceived by pathways, such as Delta/Notch, Wnt/ $\beta$-catenin and Wnt/PCP that regulate both expression of LR axis-specifying genes and morphogenesis of LRO (Raya et al., 2004, Walentek et al., 2012, Walentek et al., 2013). These $\mathrm{pH}$-perceiving signaling pathways have been suggested to act in conjunction to drive the asymmetric gene expression. Mouse mutants for Delta-like1or double mutants for Notch1 and Notch2 exhibit defects in laterality due to the loss of both earlier symmetric and later left-sided expression of Nodal (Krebs et al., 2003, Przemeck et al., 2003, Raya et al., 2003) and pharmacological inhibition of the Delta/Notch signaling in mouse results in loss of expression of Gdf1, Cerl2, but also Wnt3 around LRO (Kitajima et al., 2013). Notch signaling was also shown to directly regulate expression of Pitx2 in Xenopus and Cerberus ortholog (Charon) in zebrafish and downregulation of this pathway causes randomization of left and right sides and subsequent defects in organ situs (Gourronc et al., 2007, Raya et al., 2003, Sakano et al., 2010). Conversely, Wnt3 mouse mutants show displaced organs caused by the loss of expression of the Notch ligand Delta-like1 and loss of expression of Nodal (Nakaya et al., 2005). The flux generated by ion channels and proton pumps thus seems to be perceived by downstream signaling pathways to further regulate expression of laterality-specifying factors.

In parallel, the $\mathrm{pH}$-perceiving pathways further control morphogenesis of the LRO. Pharmacological inhibition or knockdown of $\mathrm{H}^{+} / \mathrm{K}^{+}$-ATPase in Xenopus leads to alterations in expression of LR asymmetry-specifying factors, organ situs and the loss of the leftward flow (Walentek et al., 2012). Compromised leftward flow is due to the affection of the Wnt/ $\beta$-catenin-regulated expression of the motile cilia-associated factor FoxJ1 and the Wnt/PCP-regulated antero-posterior polarization of cilia in the LRO (Walentek et al.,
2012). Concordantly, in zebrafish, downregulation of Wnt/ $\beta$-catenin signaling leads to shorter and fewer cilia in the LRO due to downregulation of FoxJ1a expression (Caron et al., 2012, Zhu et al., 2015). Apart from Wnt signaling, modulation of the Delta/Notch pathway also affects morphogenesis of the LRO, namely the ciliary length as reduction of Delta/Notch signaling produces shorter cilia, while its overactivation produces longer cilia (Lopes et al., 2010). Either shortening or lengthening of the cilia affects directionality and speed of the fluid flow and proper asymmetric expression of the Cerberus homolog Charon, pointing to the fine-tuning of the level of Delta/Notch signaling for proper LRO morphogenesis (Lopes et al., 2010).

Pathways comprising $\mathrm{H}^{+} / \mathrm{K}^{+}$-ATPase, Delta/Notch, Wnt $/ \beta$-catenin and Wnt/PCP seem to be a widespread link between the pre-LRO events and the asymmetric expression of Nodal. These pathways are likely directly associated with the formation of the LRO in vertebrates and their action is proposed to take place also in case of amphioxus (Fig. 4). In support for this proposal, $\mathrm{H}^{+} / \mathrm{K}^{+}$-ATPase has been implicated in the early steps of LR asymmetry specification in the sea urchin and pharmacological inhibition of this proton pump phenocopies inhibition of Delta/Notch signaling (Bessodes et al., 2012), suggesting that the role for $\mathrm{H}^{+} / \mathrm{K}^{+}$-ATPase acting through Delta/Notch signaling is a shared deuterostome character. Delta, Notch and several Wnt signaling members show expression in the dorsolateral archenteron in amphioxus at late gastrula and early neurula stages, although, indeed, careful examination of their expression at stages of the proposed LRO is pending (Holland et al., 2001, Rasmussen et al., 2007, Schubert et al., 2000, Wang et al., 2016, Yu et al., 2007). Long-period pharmacological inhibition of Delta/Notch signaling in amphioxus results in alteration of somitic development and the loss of larval body segmentation, although the effect on LR asymmetry is unknown due to inhibition of this pathway at stages of both LR asymmetry specification and separation of somites from archenteron (Onai et al., 2015). Nonetheless, given the presence of the ion flux prior to the occurrence of the LRO across deuterostomes and its use by amphioxus embryos, Delta/Notch, Wnt/ $\beta$-catenin and Wnt/PCP are candidate pathways to regulate amphioxus LR asymmetry through establishment of LRO and activation of Cerberus and/or Nodal expression.
Fig. 4. Early cues proposed to play role in left-right (LR) axis specification. Early cues incorporate the proposed generation of ion flux produced by $\mathrm{H}^{+} / \mathrm{K}^{+}$-ATPase and other ion channels and its perception by Wnt/ß-catenin, Wnt/PCP and Delta/Notch pathways to trigger asymmetric expression of Cerberus and/or Nodal. At the same time, these pathways likely regulate development of the $L R$ organizer that further impacts on the asymmetric expression of Cerberus and/or Nodal. Blue color marks unverified but proposed features and interactions.

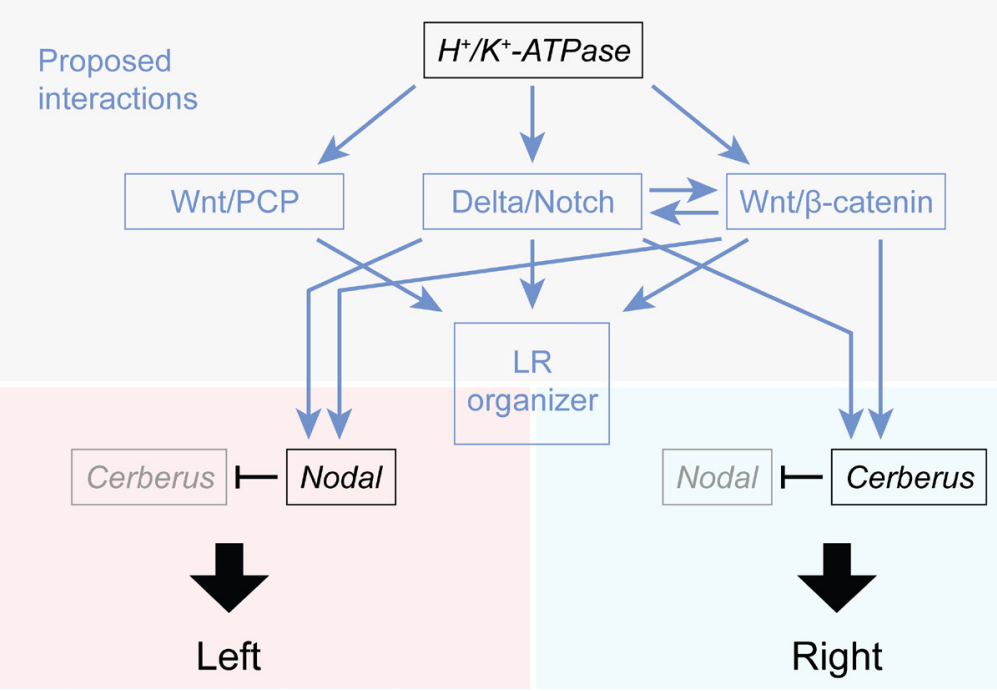




\section{Prospects for amphioxus and implications for deuterostomes}

Asymmetric morphology of the amphioxus larva is a peculiarity among extant animals. Yet, mechanisms underlying LR axis establishment in amphioxus have been deciphering only recently and the molecular pathways and cellular processes standing behind breaking of the bilateral symmetry are currently unknown. Several lines of evidence, stemming from comparison with vertebrate or ambulacrarian development as well as from gene expression studies in amphioxus, point to the presence of the LRO in amphioxus. As development of LRO is dependent on signaling from several pathways, concomitant identification of interactions between individual factors of these pathways will give a more thorough view at mechanisms standing behind LR axis specification in this animal. Research in amphioxus has long been hindered by difficulties in effective genetic manipulations. Although still difficult, recent advances in generating transgenic reporter and knockout lines seem to pave the way towards untangling not only aspects of LR axis establishment but also other aspects of amphioxus embryonic development (Kozmikova and Kozmik, 2015, Li et al., 2017).

Amphioxus represents an invertebrate relative of vertebrates and shares a common chordate body plan. At the same time, it belongs to the lineage that may be most informative for explaining the events that occurred after the dorso-ventral inversion. Mechanisms of LR asymmetry specification and LR axis establishment in amphioxus that await to be deciphered will therefore have a twofold impact: 1) compared with vertebrates to trace the invertebrate-to-vertebrate transition, and 2) compared with ambulacrarians to shed light on the dorso-ventral inversion.

One such example might be the relative position of the proposed LRO in the amphioxus body. If we deduce presence of LROs from expression patterns of Nodalorthologs, there seems to be a marked difference in their position across deuterostomes. While Nodal is expressed asymmetrically in the archenteron tip in sea urchin embryos, it is expressed at the posterior portion of the notochord close to the former position of blastopore in vertebrates. Judging from expression patterns of Nodal and Cerberus in the anterior part of the archenteron, the proposed amphioxus LRO resembles that of the sea urchin. The situation in amphioxus thus may reflect ancestral deuterostome state in positioning LROs, while the posteriorly placed LROs would be an evolutionary novelty of vertebrates (Tisler et al., 2016). According to this scenario, amphioxus LRO would represent an intermediate step between the ambulacrarian and vertebrate LROs. In support for this argument, expression of Cerberus and Nodal in the dorso-lateral portions of the amphioxus archenteron with a lack of expression of these factors medially during early stages of LR specification is reminiscent of the situation in vertebrates. This suggests presence of a vertebrate-like rather than an ambulacrarian-like LRO in amphioxus. However, at the same time, the placement of the proposed LRO in amphioxus correlates spatially with the position of developing somites and pharynx, both of which display early and marked LR asymmetries. Placement of the LRO close to tissues that need to respond to side-specific cues can be advantageous in that the sidednessdetermining signals may influence adjacent tissues directly and thus much faster, without the need of any long-range transfer that takes place in vertebrates, where the laterality signal is transferred from the LRO to the lateral plate mesoderm. This could be beneficial in case of need of rapid development and functionality of the feeding apparatus. Concordantly, the amphioxus larva is able to ingest and process food particles already at the age of one or two days reflecting the need of the rapid establishment of morphological LR asymmetries during very early larval stages.

This example represents just one comparative aspect of amphioxus LR axis establishment, but many more are awaited in the near future offering bright prospects for uncovering specificities as well as generalities of deuterostome LR asymmetry development. In this sense, identification of cues driving the asymmetric activity of $L R$ axis specifying factors either directly through regulation of their expression (on/off) or indirectly through establishment of the LRO and the ciliary-mediated fluid flow (directionality of expression), would be most desired to understand the development and evolution of deuterostome LR axis establishment.

\section{Conflict of interests}

I declare that I have no competing interests.

\section{Acknowledgements}

VS is supported by the Czech Science Foundation (GACR 14-20839P), by the Ministry of Education, Youth and Sports of the Czech Republic (LO1419) and the IMG institutional support RVO68378050. Many thanks to $M$. Levin for the discussion on inhibitors of ion channels, to Z. Kozmik, the editor of this special issue, and to two anonymous reviewers for their helpful comments on this work.

\section{References}

ADACHI, H., SAIJOH, Y., MOCHIDA, K., OHISHI, S., HASHIGUCHI, H., HIRAO, A and HAMADA, $\mathrm{H}$. (1999). Determination of left/right asymmetric expression of nodalby a left side-specific enhancer with sequence similarity to a lefty-2enhancer. Genes Dev 13: 1589-1600

ALDEA, D., LEON, A., BERTRAND, S. and ESCRIVA, H. (2015). Expression of Fox genes in the cephalochordate Branchiostoma lanceolatum. Front Ecol Evol3: 80.

ARENDT, D. and NUBLER-JUNG, K. (1994). Inversion of dorsoventral axis? Nature $371: 26$.

BARDET, P.L., SCHUBERT, M., HORARD, B., HOLLAND, L.Z., LAUDET, V., HOLLAND, N.D. and VANACKER, J.M. (2005). Expression of estrogen-receptor related receptors in amphioxus and zebrafish: implications for the evolution of posterior brain segmentation at the invertebrate-to-vertebrate transition. EvolDev7:223-233.

BERTRAND, S., ALDEA, D., OULION, S., SUBIRANA, L., DE LERA, A.R., SOMORJAI, I. and ESCRIVA, H. (2015). Evolution of the role of RA and FGF signals in the control of somitogenesis in chordates. PLoS One 10: e0136587.

BESSODES, N., HAILLOT, E., DUBOC, V., ROTTINGER, E., LAHAYE, F. and LEP. AGE, T. (2012). Reciprocal signaling between the ectoderm and a mesendodermal left-right organizer directs left-right determination in the sea urchin embryo. PLoS Genet 8: e1003121.

BLUM, M., FEISTEL, K., THUMBERGER, T. and SCHWEICKERT, A. (2014a). The evolution and conservation of left-right patterning mechanisms. Development 141: 1603-1613.

BLUM, M., SCHWEICKERT, A., VICK, P., WRIGHT, C.V. and DANILCHIK, M.V (2014b). Symmetry breakage in the vertebrate embryo: when does it happen and how does it work? Dev Biol 393: 109-123.

BLUM, M., WEBER, T., BEYER, T. and VICK, P. (2009). Evolution of leftward flow. Semin Cell Dev Biol 20: 464-471.

CANDIANI, S., HOLLAND, N.D., OLIVERI, D., PARODI, M. and PESTARINO, M (2008). Expression of the amphioxus Pit-1 gene (AmphiPOU1F1/Pit-1) exclusively in the developing preoral organ, a putative homolog of the vertebrate adenohypophysis. Brain Res Bull 75: 324-330.

CANDIANI, S., OLIVERI, D., PARODI, M., BERTINI, E. and PESTARINO, M. (2006) Expression of AmphiPOU-IVin the developing neural tube and epidermal sensory neural precursors in amphioxus supports a conserved role of class IV POU genes in the sensory cells development. Dev Genes Evol 216: 623-633. 
CARON, A., XU, X. and LIN, X. (2012). Wnt/beta-catenin signaling directly regulates Foxj1 expression and ciliogenesis in zebrafish Kupffer's vesicle. Development 139: 514-524.

CHEN, X., WEISBERG, E., FRIDMACHER, V., WATANABE, M., NACO, G. and WHITMAN, M. (1997). Smad4 and FAST-1 in the assembly of activin-responsive factor. Nature 389: 85-89.

CHOCRON, S., VERHOEVEN, M.C., RENTZSCH, F., HAMMERSCHMIDT, M. and BAKKERS, J. (2007). Zebrafish Bmp4 regulates left-right asymmetry at two distinct developmental time points. Dev Biol 305: 577-588.

CONKLIN, E.G. (1932). The embryology of amphioxus. J Morphol 54: 69-151.

COUTELIS, J.B., GONZALEZ-MORALES, N., GEMINARD, C. and NOSELLI, S. (2014). Diversity and convergence in the mechanisms establishing L/R asymmetry in metazoa. EMBO Rep 15: 926-937.

DE ROBERTIS, E.M. and SASAI, Y. (1996). A common plan for dorsoventral patterning in Bilateria. Nature 380: 37-40.

DUBOC, V., ROTTINGER, E., LAPRAZ, F., BESNARDEAU, L. and LEPAGE, T. (2005). Left-right asymmetry in the sea urchin embryo is regulated by nodal signaling on the right side. Dev Cell 9: 147-158.

GOURRONC, F., AHMAD, N., NEDZA, N., EGGLESTON, T. and REBAGLIATI, M. (2007). Nodal activity around Kupffer's vesicle depends on the T-box transcription factors Notail and Spadetail and on Notch signaling. Dev Dyn 236: 2131-2146.

GRANDE, C., MARTIN-DURAN, J.M., KENNY, N.J., TRUCHADO-GARCIA, M. and HEJNOL, A. (2014). Evolution, divergence and loss of the Nodal signalling pathway: new data and a synthesis across the Bilateria. Int J Dev Biol 58: 521-532.

GRANDE, C. and PATEL, N.H. (2009). Nodal signalling is involved in left-right asymmetry in snails. Nature 457: 1007-1011.

HATSCHEK, B. (1893). The Amphioxus and Its Development. MacMillan and Co., New York.

HIBINO, T., ISHII, Y., LEVIN, M. and NISHINO, A. (2006). Ion flow regulates left-right asymmetry in sea urchin development. Dev Genes Evol 216: 265-276.

HIRAKOW, R. and KAJITA, N. (1991). Electron microscopic study of the development of amphioxus, Branchiostoma belcheri tsingtauense: the gastrula. J Morphol 207: 27-52.

HIROKAWA, N., TANAKA, Y., OKADA, Y. and TAKEDA, S. (2006). Nodal flow and the generation of left-right asymmetry. Cell 125: 33-45.

HOLLAND, L.Z., RACHED, L.A., TAMME, R., HOLLAND, N.D., KORTSCHAK, D., INOKO, H., SHIINA, T., BURGTORF, C. and LARDELLI, M. (2001). Characterization and developmental expression of the amphioxus homolog of Notch (AmphiNotch): evolutionary conservation of multiple expression domains in amphioxus and vertebrates. Dev Biol 232: 493-507.

HOLLAND, N.D. and HOLLAND, L.Z. (2010). Laboratory spawning and development of the Bahama lancelet, Asymmetron lucayanum (cephalochordata): fertilization through feeding larvae. Biol Bull 219: 132-141.

IGAWA, T., NOZAWA, M., SUZUKI, D.G., REIMER, J.D., MOROV, A.R., WANG, Y., HENMI, Y. and YASUI, K. (2017). Evolutionary history of the extant amphioxus lineage with shallow-branching diversification. Sci Rep 7: 1157.

KAJI, T., REIMER, J.D., MOROV, A.R., KURATANI, S. and YASUI, K. (2016). Amphioxus mouth after dorso-ventral inversion. Zool Lett 2: 2.

KAJI, T., SHIMIZU, K., ARTINGER, K.B. and YASUI, K. (2009). Dynamic modification of oral innervation during metamorphosis in Branchiostoma belcheri, the oriental lancelet. Biol Bull 217: 151-160.

KATSU, K., TATSUMI, N., NIKI, D., YAMAMURA, K. and YOKOUCHI, Y. (2013). Multi-modal effects of BMP signaling on Nodal expression in the lateral plate mesoderm during left-right axis formation in the chick embryo. Dev Bio/374:71-84.

KITAJIMA, K., OKI, S., OHKAWA, Y., SUMI, T. and MENO, C. (2013). Wnt signaling regulates left-right axis formation in the node of mouse embryos. Dev Biol 380: 222-232.

KOZMIKOVA, I. and KOZMIK, Z. (2015). Gene regulation in amphioxus: An insight from transgenic studies in amphioxus and vertebrates. Mar Genomics 24: 159-166.

KREBS, L.T., IWAI, N., NONAKA, S., WELSH, I.C., LAN, Y., JIANG, R., SAIJOH, Y., O'BRIEN, T.P., HAMADA, H. and GRIDLEY, T. (2003). Notch signaling regulates left-right asymmetry determination by inducing Nodal expression. Genes Dev 17: 1207-1212.

KURODA, R., ENDO, B., ABE, M. and SHIMIZU, M. (2009). Chiral blastomere arrangement dictates zygotic left-right asymmetry pathway in snails. Nature 462: 790-794.
LACALLI, T.C. (2008). Head organization and the head/trunk relationship in protochordates: problems and prospects. Integr Comp Biol 48: 620-629.

LE PETILLON, Y., OULION, S., ESCANDE, M.L., ESCRIVA, H. and BERTRAND, S. (2013). Identification and expression analysis of BMP signaling inhibitors genes of the DAN family in amphioxus. Gene Expr Patterns 13: 377-383.

LEVIN, M., THORLIN, T., ROBINSON, K.R., NOGI, T. and MERCOLA, M. (2002). Asymmetries in $\mathrm{H}^{+} / \mathrm{K}^{+}$-ATPase and cell membrane potentials comprise a very early step in left-right patterning. Cell 111: 77-89.

LI, G., LIU, X., XING, C., ZHANG, H., SHIMELD, S.M. and WANG, Y. (2017). CerberusNodal-Lefty-Pitx signaling cascade controls left-right asymmetry in amphioxus. Proc Natl Acad Sci USA 114: 3684-3689.

LOPES, S.S., LOURENCO, R., PACHECO, L., MORENO, N., KREILING, J. and SAUDE, L. (2010). Notch signalling regulates left-right asymmetry through ciliary length control. Development 137: 3625-3632.

LUO, Y.J. and SU, Y.H. (2012). Opposing nodal and BMP signals regulate left-right asymmetry in the sea urchin larva. PLoS Biol 10: e1001402.

MARTIN-DURAN, J.M., VELLUTINI, B.C. and HEJNOL, A. (2016). Embryonic chirality and the evolution of spiralian left-right asymmetries. Phil. Trans. R. Soc. B 371: 20150411.

MCDOWELL, G., RAJADURAI, S. and LEVIN, M. (2016). From cytoskeletal dynamics to organ asymmetry: a nonlinear, regulative pathway underlies left-right patterning. Phil. Trans. R. Soc. B 371: 20150409.

MINE, N., ANDERSON, R.M. and KLINGENSMITH, J. (2008). BMP antagonism is required in both the node and lateral plate mesoderm for mammalian left-right axis establishment. Development 135: 2425-2434

MINGUILLON, C. and GARCIA-FERNANDEZ, J. (2002). The single amphioxus Mox gene: insights into the functional evolution of Mox genes, somites, and the asymmetry of amphioxus somitogenesis. Dev Biol 246: 455-465.

MOROKUMA, J., UENO, M., KAWANISHI, H., SAIGA, H. and NISHIDA, H. (2002). HrNodal, the ascidian nodal-related gene, is expressed in the left side of the epidermis, and lies upstream of HrPitx. Dev Genes Evol 212: 439-446.

NAKAMURA, T. and HAMADA, H. (2012). Left-right patterning: conserved and divergent mechanisms. Development 139: 3257-3262.

NAKAMURA, T., SAITO, D., KAWASUMI, A., SHINOHARA, K., ASAI, Y., TAKAOKA, K., DONG, F., TAKAMATSU, A., BELO, J.A., MOCHIZUKI, A. et al., (2012). Fluid flow and interlinked feedback loops establish left-right asymmetric decay of Cerl2 mRNA. Nat Commun 3: 1322.

NAKAYA, M.A., BIRIS, K., TSUKIYAMA, T., JAIME, S., RAWLS, J.A. and YAMAGUCHI, T.P. (2005). Wnt3a links left-right determination with segmentation and anteroposterior axis elongation. Development 132: 5425-5436.

NAMIGAI, E.K., KENNY, N.J. and SHIMELD, S.M. (2014). Right across the tree of life: the evolution of left-right asymmetry in the Bilateria. Genesis 52: 458-470.

NORRIS, D.P., BRENNAN, J., BIKOFF, E.K. and ROBERTSON, E.J. (2002). The Foxh1-dependent autoregulatory enhancer controls the level of Nodal signals in the mouse embryo. Development 129: 3455-3468.

ONAI, T., ARAMAKI, T., INOMATA, H., HIRAI, T. and KURATANI, S. (2015). On the origin of vertebrate somites. Zool Lett 1: 33 .

ONAI, T., YU, J.K., BLITZ, I.L., CHO, K.W. and HOLLAND, L.Z. (2010). Opposing Nodal/Vg1 and BMP signals mediate axial patterning in embryos of the basal chordate amphioxus. Dev Biol 344: 377-389.

OSADA, S.I., SAIJOH, Y., FRISCH, A., YEO, C.Y., ADACHI, H., WATANABE, M. WHITMAN, M., HAMADA, H. and WRIGHT, C.V. (2000). Activin/nodal responsiveness and asymmetric expression of a Xenopus nodal-related gene converge on a FAST-regulated module in intron 1. Development 127: 2503-2514.

PIEDRA, M.E. and ROS, M.A. (2002). BMP signaling positively regulates Nodal expression during left right specification in the chick embryo. Development 129 3431-3440.

POGODA, H.M., SOLNICA-KREZEL, L., DRIEVER, W. and MEYER, D. (2000) The zebrafish forkhead transcription factor FoxH1/Fast1 is a modulator of nodal signaling required for organizer formation. Curr Biol 10: 1041-1049.

PRZEMECK, G.K., HEINZMANN, U., BECKERS, J. and HRABE DE ANGELIS, M (2003). Node and midline defects are associated with left-right development in Delta1 mutant embryos. Development 130: 3-13.

RASMUSSEN, S.L., HOLLAND, L.Z., SCHUBERT, M., BEASTER-JONES, L. and HOLLAND, N.D. (2007). Amphioxus AmphiDelta: evolution of Delta protein struc- 
ture, segmentation, and neurogenesis. Genesis 45: 113-122.

RAYA, A., KAWAKAMI, Y., RODRIGUEZ-ESTEBAN, C., BUSCHER, D., KOTH, C.M. ITOH, T., MORITA, M., RAYA, R.M., DUBOVA, I., BESSA, J.G. et al., (2003). Notch activity induces Nodal expression and mediates the establishment of left-right asymmetry in vertebrate embryos. Genes Dev 17: 1213-1218.

RAYA, A., KAWAKAMI, Y., RODRIGUEZ-ESTEBAN, C., IBANES, M., RASSKINGUTMAN, D., RODRIGUEZ-LEON, J., BUSCHER, D., FEIJO, J.A. and IZPISUA BELMONTE, J.C. (2004). Notch activity acts as a sensor for extracellular calcium during vertebrate left-right determination. Nature 427: 121-128.

SAIJOH, Y., ADACHI, H., SAKUMA, R., YEO, C.Y., YASHIRO, K., WATANABE, M., HASHIGUCHI, H., MOCHIDA, K., OHISHI, S., KAWABATA, M. et al., (2000). Leftright asymmetric expression of lefty2 and nodal is induced by a signaling pathway that includes the transcription factor FAST2. Mol Cell 5: 35-47.

SAKANO, D., KATO, A., PARIKH, N., MCKNIGHT, K., TERRY, D., STEFANOVIC, B. and KATO, Y. (2010). BCL6 canalizes Notch-dependent transcription, excluding Mastermind-like1 from selected target genes during left-right patterning. Dev Cell 18: 450-462.

SCHLANGE, T., ARNOLD, H.H. and BRAND, T. (2002). BMP2 is a positive regulator of Nodal signaling during left-right axis formation in the chicken embryo. Development 129: 3421-3429.

SCHUBERT, M., HOLLAND, L.Z., PANOPOULOU, G.D., LEHRACH, H. and HOLLAND, N.D. (2000). Characterization of amphioxus AmphiWnt8: insights into the evolution of patterning of the embryonic dorsoventral axis. Evol Dev 2: 85-92.

SCHUBERT, M., YU, J.K., HOLLAND, N.D., ESCRIVA, H., LAUDET, V. and HOLLAND, L.Z. (2005). Retinoic acid signaling acts via Hox1 to establish the posterior limit of the pharynx in the chordate amphioxus. Development 132: 61-73.

SCHWEICKERT, A., VICK, P., GETWAN, M., WEBER, T., SCHNEIDER, I., EBERHARDT, M., BEYER, T., PACHUR, A. and BLUM, M. (2010). The nodal inhibitor Coco is a critical target of leftward flow in Xenopus. Curr Biol 20: 738-743.

SHEN, M.M. (2007). Nodal signaling: developmental roles and regulation. Development 134: 1023-1034.

SHIMELD, S.M. and LEVIN, M. (2006). Evidence for the regulation of left-right asymmetry in Ciona intestinalis by ion flux. Dev Dyn 235: 1543-1553.

SHIRATORI, H., SAKUMA, R., WATANABE, M., HASHIGUCHI, H., MOCHIDA, K., SAKAI, Y., NISHINO, J., SAIJOH, Y., WHITMAN, M. and HAMADA, H. (2001). Two-step regulation of left-right asymmetric expression of Pitx2: initiation by nodal signaling and maintenance by Nkx2. Mol Cell 7: 137-149.

SHU, X., HUANG, J., DONG, Y., CHOI, J., LANGENBACHER, A. and CHEN, J.N. (2007). Na,K-ATPase alpha2 and Ncx4a regulate zebrafish left-right patterning. Development 134: 1921-1930.

SOUKUP, V. and KOZMIK, Z. (2016). Zoology: A New Mouth for Amphioxus. Curr Biol 26: R367-R368.

SOUKUP, V., YONG, L.W., LU, T.M., HUANG, S.W., KOZMIK, Z. and YU, J.K (2015). The Nodal signaling pathway controls left-right asymmetric development in amphioxus. Evodevo 6: 5.

STACH, T. (2000). Microscopic anatomy of developmental stages of Branchiostoma lanceolatum (Cephalochordata, Chordata). In Bonner Zoologische Monographien, vol. 47 (ed. RHEINWALD, G.). Zoologisches Forschungsinstitut und Museum Alexander Koenig, Bonn, pp.111.

SU, Y.H. (2014). Telling left from right: left-right asymmetric controls in sea urchins. Genesis 52: 269-278.

TAKEMOTO, A., MIYAMOTO, T., SIMONO, F., KUROGI, N., SHIRAE-KURABAYASHI, M., AWAZU, A., SUZUKI, K.T., YAMAMOTO, T. and SAKAMOTO, N. (2016). Cilia play a role in breaking left-right symmetry of the sea urchin embryo. Genes Cells 21: 568-578.

TISLER, M., WETZEL, F., MANTINO, S., KREMNYOV, S., THUMBERGER, T., SCHWEICKERT, A., BLUM, M. and VICK, P. (2016). Cilia are required for asymmetric nodal induction in the sea urchin embryo. BMC Dev Biol 16: 28.

VAN WIJHE, J.W. (1925). On the temporary presence of the primary mouth-opening in the larva of amphioxus, and the occurrence of three postoral papillae, which are probably homologous with those of the larva of ascidians. Proc Kon Akad Wetensch Amsterdam 29: 286-295.

VANDENBERG, L.N. and LEVIN, M. (2013). A unified model for left-right asymmetry? Comparison and synthesis of molecular models of embryonic laterality. Dev Biol 379: 1-15.

VENKATESH, T.V., HOLLAND, N.D., HOLLAND, L.Z., SU, M.T. and BODMER, R. (1999). Sequence and developmental expression of amphioxus AmphiNk2-1: insights into the evolutionary origin of the vertebrate thyroid gland and forebrain. Dev Genes Evol 209: 254-259.

WALENTEK, P., BEYER, T., THUMBERGER, T., SCHWEICKERT, A. and BLUM, M (2012). ATP4a is required for Wnt-dependent Foxj1 expression and leftward flow in Xenopus left-right development. Cell Rep 1: 516-527.

WALENTEK, P., SCHNEIDER, I., SCHWEICKERT, A. and BLUM, M. (2013). Wnt11b is involved in cilia-mediated symmetry breakage during Xenopus left-right development. PLoS One 8: e73646.

WANG, J., LI, G., QIAN, G.H., HUA, J.H. and WANG, Y.Q. (2016). Expression analysis of eight amphioxus genes involved in the Wnt/beta-catenin signaling pathway. Zool Res 37: 136-143.

WANG, Y., ZHANG, P.J., YASUI, K. and SAIGA, H. (2002). Expression of Bblhx3, a LIM-homeobox gene, in the development of amphioxus Branchiostoma belcheri tsingtauense. Mech Dev 117: 315-319.

WATANABE, H., SCHMIDT, H.A., KUHN, A., HOGER, S.K., KOCAGOZ, Y., LAUMANNLIPP, N., OZBEK, S. and HOLSTEIN, T.W. (2014). Nodal signalling determines biradial asymmetry in Hydra. Nature 515: 112-115.

WILLEY, A. (1891). The later larval development of amphioxus. Quart J Micr Sci 32: $183-234$

WILLEY, A. (1894). Amphioxus and the ancestry of the vertebrates. MacMillan and Co., New York.

WLIZLA, M. (2011). Evolution of Nodal signaling in deuterostomes: Insights from Saccoglossus kowalewskii, Ph.D. thesis (University of Chicago, USA)

YASUI, K., KAJI, T., MOROV, A.R. and YONEMURA, S. (2014). Development of oral and branchial muscles in lancelet larvae of Branchiostoma japonicum. J Morphol 275: 465-477.

YASUI, K., TABATA, S., UEKI, T., UEMURA, M. and ZHANG, S.C. (1998). Early development of the peripheral nervous system in a lancelet species. J Comp Neurol 393: 415-425.

YASUI, K., ZHANG, S., UEMURA, M. and SAIGA, H. (2000). Left-right asymmetric expression of BbPtx, a Ptx-related gene, in a lancelet species and the developmental left-sidedness in deuterostomes. Development 127: 187-195.

YU, J.K., HOLLAND, L.Z. and HOLLAND, N.D. (2002a). An amphioxus nodal gene (AmphiNodal) with early symmetrical expression in the organizer and mesoderm and later asymmetrical expression associated with left-right axis formation. Evol Dev 4: 418-425

YU, J.K., HOLLAND, L.Z., JAMRICH, M., BLITZ, I.L. and HOLLAN, N.D. (2002b) AmphiFoxE4, an amphioxus winged helix/forkhead gene encoding a protein closely related to vertebrate thyroid transcription factor-2: expression during pharyngeal development. Evol Dev 4: 9-15.

YU, J.K., SATOU, Y., HOLLAND, N.D., SHIN, I.T., KOHARA, Y., SATOH, N., BRONNERFRASER, M. and HOLLAND, L.Z. (2007). Axial patterning in cephalochordates and the evolution of the organizer. Nature 445: 613-617.

YU, X., NG, C.P., HABACHER, H. and ROY, S. (2008). Foxj1 transcription factors are master regulators of the motile ciliogenic program. Nat Genet 40: 1445-1453.

ZHANG, Y. and MAO, B. (2010). Embryonic expression and evolutionary analysis of the amphioxus Dickkopf and Kremen family genes. J Genet Genomics 37:637-645.

ZHU, P., XU, X. and LIN, X. (2015). Both ciliary and non-ciliary functions of Foxj1a confer Wnt/beta-catenin signaling in zebrafish left-right patterning. Biol Open 4 1376-1386. 


\section{Further Related Reading, published previously in the Int. J. Dev. Biol.}

Evolution, divergence and loss of the Nodal signalling pathway: new data and a synthesis across the Bilateria Cristina Grande, José María Martín-Durán, Nathan J. Kenny, Marta Truchado-García and Andreas Hejnol Int. J. Dev. Biol. (2014) 58: 521-532

The Lophotrochozoan TGF- $\beta$ signalling cassette - diversification and conservation in a key signalling pathway

Nathan J. Kenny,Erica K.O. Namigai, Peter K. Dearden, Jerome H.L. Hui, Cristina Grande and Sebastian M. Shimeld

Int. J. Dev. Biol. (2014) 58: 533-549

Generating asymmetries in the early vertebrate embryo: the role of the Cerberus-like family José António Belo, Ana C. Silva, Ana-Cristina Borges, Mário Filipe, Margaret Bento, Lisa Gonçalves, Marta Vitorino, Ana-Marisa Salgueiro, Vera Texeira, Ana T. Tavares and Sara Marques Int. J. Dev. Biol. (2009) 53: 1399-1407

From the American to the European amphioxus: towards experimental Evo-Devo at the origin of chordates

Jordi Garcia-Fernàndez, Senda Jiménez-Delgado, Juan Pascual-Anaya, Ignacio Maeso, Manuel Irimia, Carolina Minguillón, Èlia Benito-Gutiérrez, Josep Gardenyes, Stéphanie Bertrand and Salvatore D'Aniello

Int. J. Dev. Biol. (2009) 53: 1359-1366

Amphioxus Hox genes: insights into evolution and development.

$\mathrm{J}$ Garcia-Fernàndez and $\mathrm{P}$ W Holland

Int. J. Dev. Biol. (1996) 40: S71-S72

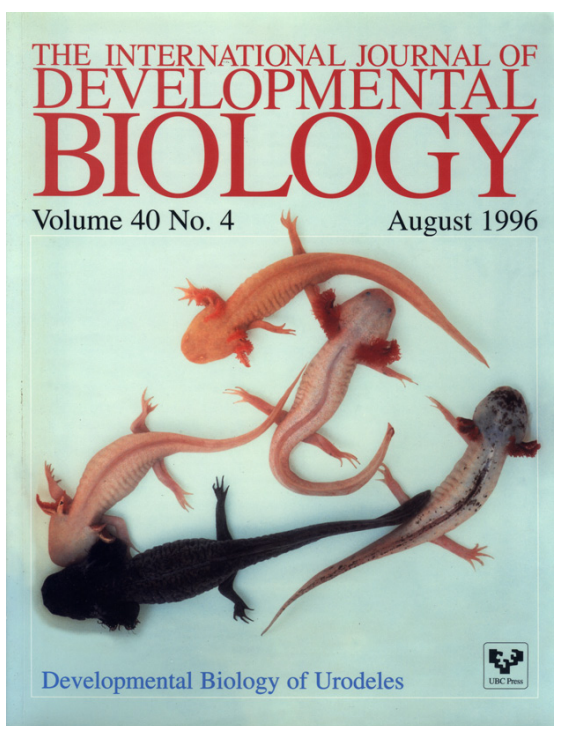

5 yr ISI Impact Factor $(2013)=2.879$

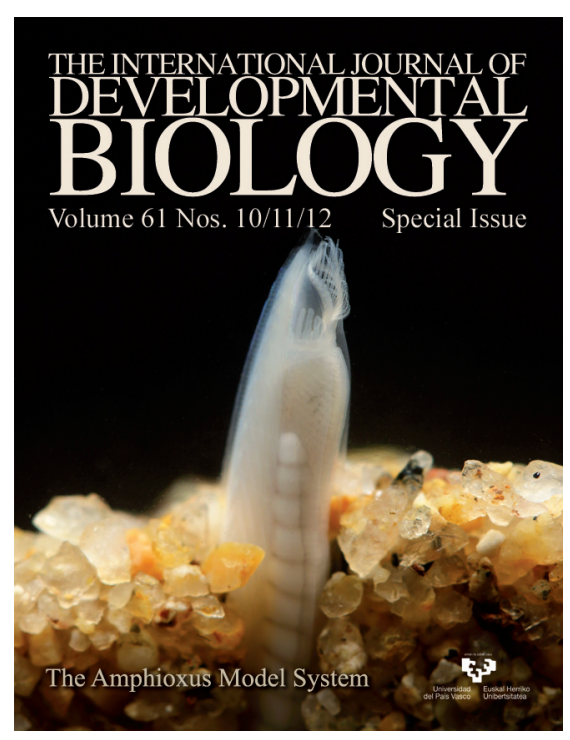

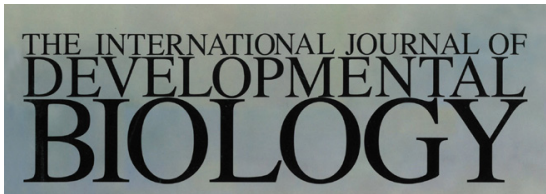
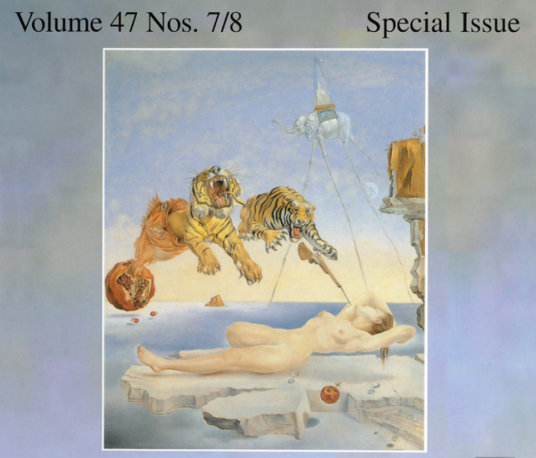

Evolution \& Development

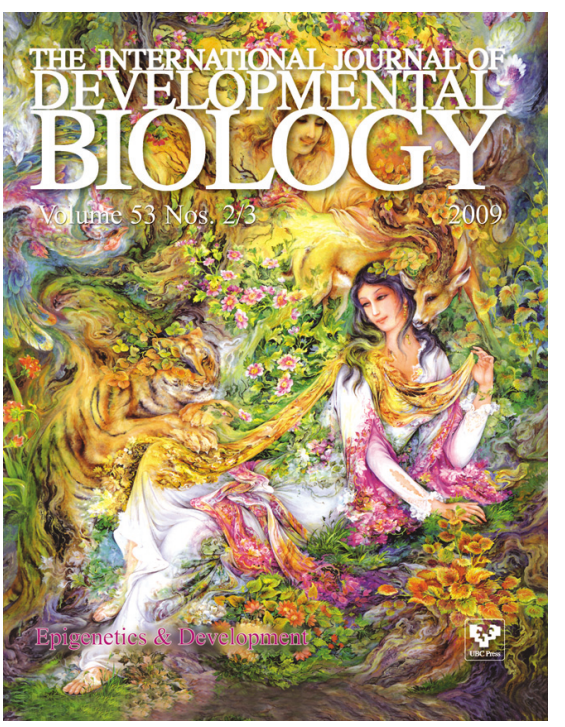

